\title{
Difference in Calcium Dependency of Insulin, Glucagon and Somatostatin Secretion in Response to Glibenclamide in Perfused Rat Pancreas
}

\author{
S. Efendić, V.Grill, A. Nylén and C.-G.Östensson \\ Department of Endocrinology, Karolinska Hospital, Stockholm, Sweden
}

Summary. The extracellular calcium requirements for insulin, glucagon and somatostatin release induced by $1 \mu \mathrm{g} / \mathrm{ml}$ of glibenclamide have been compared in the perfused, isolated rat pancreas. In the absence of glucose, the drug evoked insulin release equally well at physiological $(2.6 \mathrm{mmol} / \mathrm{l})$ and low $(0.25 \mathrm{mmol} / \mathrm{l})$ levels of total calcium. In contrast, glibenclamide evoked somatostatin release at 2.6 but not at 0.25 $\mathrm{mmol} / \mathrm{l}$ of calcium. At $2.6 \mathrm{mmol} / 1$ of calcium, glibenclamide evoked bimodal effects (stimulation followed by inhibition) on glucagon secretion. At $0.25 \mathrm{mmol} / 1$ of calcium, basal secretory rates of glucagon were elevated and a small stimulatory effect of glibenclamide was seen. Addition of $0.5 \mathrm{mmol} / 1$ of EGTA to media with low calcium concentrations uniformly abolished the A, B and D cell secretory responses to glibenclamide. The possible modulation of calcium dependency by a non-stimulatory concentration of glucose was tested by its addition at 3.3 $\mathrm{mmol} / 1$ to the perfusion media. Glucose enhanced glibenclamide-induced insulin secretion, both at 0.25 and $2.6 \mathrm{mmol} / \mathrm{l}$ of calcium. However, at $0.25 \mathrm{mmol} / 1$ of calcium, the enhancing effect of glucose was more pronounced than at $2.6 \mathrm{mmol} / 1$. At $2.6 \mathrm{mmol} / 1$ of calcium, glucose diminished the somatostatin and abolished the glucagon response to glibenclamide. At $0.25 \mathrm{mmol} / 1$ of calcium, glucose did not influence somatostatin release while the presence of the sugar diminished basal and glibenclamide-induced glucagon secretion. The present data confirm the requirement of extracellular calcium for A, B and D cell secretion, demonstrating different calcium dependencies for the cell types and indicate that this dependency can, in part, be modulated by glucose.

Key words: Insulin secretion, glucagon secretion, somatostatin secretion, calcium, glucose, sulphonylurea, paracrine interaction.
Several nutrients, hormones, ions, and drugs have been shown to stimulate the secretion of both insulin and somatostatin from the endocrine pancreas $[1,2]$. The clinically important sulphonylureas belong to the substances which promote the secretion of these two hormones [3-5] and both these actions could be relevant for their effects in diabetes.

Calcium seems to play a direct regulatory role in the secretory process of pancreatic A, B and D cells. Thus, under certain experimental conditions, calcium ions per se can stimulate secretion of all three hormones [2, 6-12]. A key role of calcium in hormone secretion is also suggested by the observation that the presence of extracellular calcium is a prerequisite for the stimulatory response induced by different secretagogues $[2,6,8]$. However, data as to whether calcium requirements differ between the respective types of hormone-secreting cells are contradictory $[6,9,13]$ or lacking.

In the present investigation, we have studied the effects of varying degrees of calcium depletion on glibenclamide-induced insulin, glucagon and somatostatin release from the perfused, isolated rat pancreas. Furthermore, we have, tested whether calcium dependency of the islet cells is subject to modulation by glucose.

\section{Materials and Methods}

\section{Animals and Perfusion System}

Male Sprague-Dawley rats (Anticimex, Solna, Sweden), weighing $200-250 \mathrm{~g}$, were used. They were fed ad libitum with a commercial pelleted diet (Anticimex). The animals were anaesthetized by an IP injection of pentobarbital ( $100 \mathrm{mg} / \mathrm{kg}$ body weight). The pancreas was isolated free from all adjacent organs by the technique of Loubatières et al. [14]. The organ was perfused by a cannula in the abdominal aorta. The perfusion medium was not allowed to re-circulate. Except for variations in calcium, it consisted of a Krebs-Ringer bicarbonate buffer solution [15], supplemented with $20 \mathrm{~g} / 1$ of bo- 


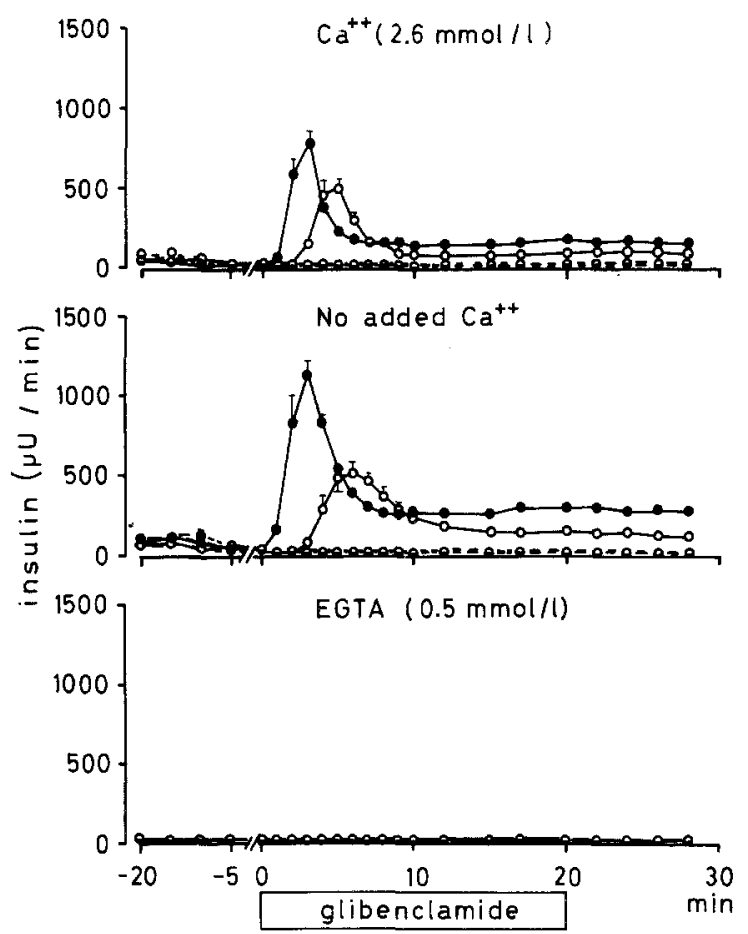

Fig. 1. Effect of variation of calcium concentrations on glibenclamide-induced insulin release in the presence or absence of $3.3 \mathrm{mmol} / 1$ of glucose. Results are expressed as mean $\pm \mathrm{SEM}$ of 6-11 experiments. $\mathrm{O}$-..- $\mathrm{O}=$ basal medium, no glucose, - basal medium, glucose $3.3 \mathrm{mmol} / 1, \mathrm{O} \longrightarrow \mathrm{O}$ perfusions with glibenclamide without glucose, enclamide together with $3.3 \mathrm{mmol} / \mathrm{l}$ of glucose (Note that basal medium results with and without glucose show extensive overlap.)

vine albumin. The buffer solution as well as the experimental modifications thereof were adjusted to $\mathrm{pH} 7.4$ before use. The system was operated at a constant flow rate of $2.5 \mathrm{ml} / \mathrm{min}$. During a $20 \mathrm{~min}$ pre-perfusion period (not indicated in the Figures) the medium always contained glucose $(3.3 \mathrm{mmol} / \mathrm{l})$, which was then omitted or continued during the subsequent 50 min of experimental perfusion. Variations in the calcium concentration of the perfusate were introduced $20 \mathrm{~min}$ before stimulation with glibenclamide and were achieved by 1) adding $\mathrm{CaCl}_{2}$ to achieve a total physiological $\mathrm{Ca}^{++}$ concentration of $2.6 \mathrm{mmol} / 1$, or 2) omitting $\mathrm{CaCl}_{2}$, or 3) supplementing the latter medium with EGTA $0.5 \mathrm{mmol} / 1$. These manipulations resulted in total calcium concentrations of 2.64 in medium 1 and $0.25 \mathrm{mmol} / \mathrm{l}$ in medium 2 as measured by atomic absorption.

\section{Chemicals}

Glibenclamide was kindly supplied by Farbwerke Hoechst, Frankfurt, FRG. Four $\mathrm{mg}$ was dissolved in $10 \mathrm{ml}$ of $5 \mathrm{mmol} / 1$ of $\mathrm{NaOH}$ and aliquots added to the test solutions. Bovine albumin and EGTA were obtained from Sigma, St Louis, Missouri, USA.

\section{Hormone Assays}

Insulin was measured radioimmunologically, using charcoal to separate bound and free antibodies [16]. The sensitivity of this assay was $8 \mathrm{mU} / 1$ and the coefficient of variation $\pm 10 \%$. Glucagon was assayed radioimmunologically using a charcoal separation tech- nique and the $30 \mathrm{~K}$ antiserum [17]. The sensitivity was about $50 \mathrm{pg} / \mathrm{ml}$ and the coefficient of variation $\pm 7 \%$. Somatostatin was determined by a radioimmunoassay using own antibodies (R 141E) $[5,18]$. The sensitivity was about $5 \mathrm{pg} / \mathrm{ml}$ and the coefficient of variation $\pm 15 \%$.

\section{Results}

\section{Effects of Glibenclamide on Hormone Secretion at a Physiological Calcium Concentration}

Insulin: Glibenclamide in the presence of $3.3 \mathrm{mmol} / \mathrm{1}$ of glucose and $2.6 \mathrm{mmol} / \mathrm{l}$ of calcium promptly stimulated insulin secretion (Fig. 1, upper panel). Stimulation of $\mathrm{B}$ cell secretion continued for the $10 \mathrm{~min}$ studied after withdrawal of the drug from the perfusion medium. When glucose was excluded from the perfusate glibenclamide still, but to a lesser extent, stimulated insulin release. Also the onset of stimulated secretion was delayed $1 \mathrm{~min}$ by glucose withdrawal.

At a low calcium concentration (i.e. no $\mathrm{CaCl}_{2}$ added to the medium), glibenclamide retained its stimulatory effect on insulin secretion (Fig. 1, middle panel). Indeed, in the presence of glucose this stimulation was more pronounced than at the normal calcium concentration. At $0.25 \mathrm{mmol} / 1$ of calcium together with $3.3 \mathrm{mmol} / 1$ of glucose, the first phase of glibenclamide-induced insulin secretion (min 0-6) was thus augmented from $354 \pm 31(n=6)$ to $617 \pm$ $55 \mu \mathrm{U} / \min (n=7)(p<0.01)$ relative to stimulation seen at $2.6 \mathrm{mmol} / \mathrm{l}$ of calcium together with the sugar. The second phase ( $\min 6-20$ ) was increased from 164 $\pm 6(n=6)$ to $297 \pm 29 \mu \mathrm{U} / \min (n=7)(p<0.01)$. In the absence of glucose, the magnitude of glibenclamide-induced insulin secretion was similar whether or not calcium had been added to the incubation media.

A further reduction of extracellular calcium by the inclusion of EGTA $(0.5 \mathrm{mmol} / \mathrm{l})$ to a medium without added calcium completely suppressed the stimulated insulin release whether tested in the presence or absence of $3.3 \mathrm{mmol} / 1$ of glucose.

Somatostatin: With $2.6 \mathrm{mmol} / 1$ of calcium, glibenclamide stimulated somatostatin release both in the presence and absence of $3.3 \mathrm{mmol} / \mathrm{l}$ of glucose (Fig. 2, upper panel). Glucose withdrawal augmented the somatostatin response. Thus, the area under the somatostatin curve was increased from $886 \pm 88$ $(n=11)$ to $1484 \pm 91 \mathrm{pg} / 20 \min (n=7)(p<0.001$; Student's t-test).

In contrast to the persistence and even augmentation of the insulin release, stimulated somatostatin release was totally abolished by the low calcium medium (Fig. 2, middle panel). This effect of low calcium was seen regardless of whether the medium contained 


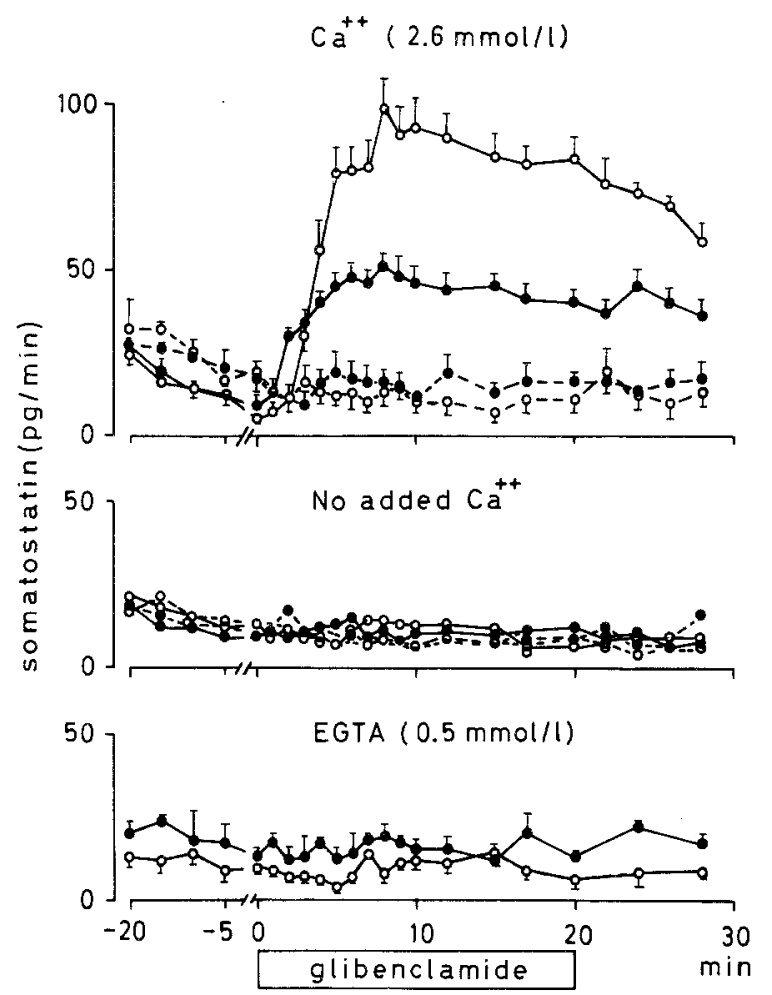

Fig. 2. Effect of variation of calcium concentrations on glibenclamide-induced somatostatin release in the presence or absence of $3.3 \mathrm{mmol} / \mathrm{l}$ of glucose. Experimental conditions and symbols as in Fig. 1

no or $3.3 \mathrm{mmol} / 1$ of glucose. The same pattern of inhibition was seen in the presence of EGTA(Fig. 2, lower panel).

Glucagon: With $2.6 \mathrm{mmol} / \mathrm{l}$ of calcium, glibenclamide induced no change in glucagon secretion in the presence of $3.3 \mathrm{mmol} / 1$ of glucose (Fig. 3, upper panel). The effect of glucopenia on glibenclamide-regulated glucagon release was complex. Omission of glucose per se caused a gradual increase of the basal secretion of glucagon. Subsequent introduction of the drug elicited an immediate peak of glucagon release, which, within $3 \mathrm{~min}$, was followed by constant suppression.

Omission of calcium in the incubation medium augmented basal glucagon secretion (Fig. 2, middle panel). Superimposed on this increased secretion, glibenclamide gave a small, evanescent stimulation in the presence of $3.3 \mathrm{mmol} / 1$ of glucose. A somewhat more marked effect of glibenclamide was observed in the absence of glucose. Whether in the absence or presence of glucose, addition of EGTA depressed basal release rates of glucagon and abolished glibencla-
$\mathrm{Ca}^{++}(2.6 \mathrm{mmol} / 1)$
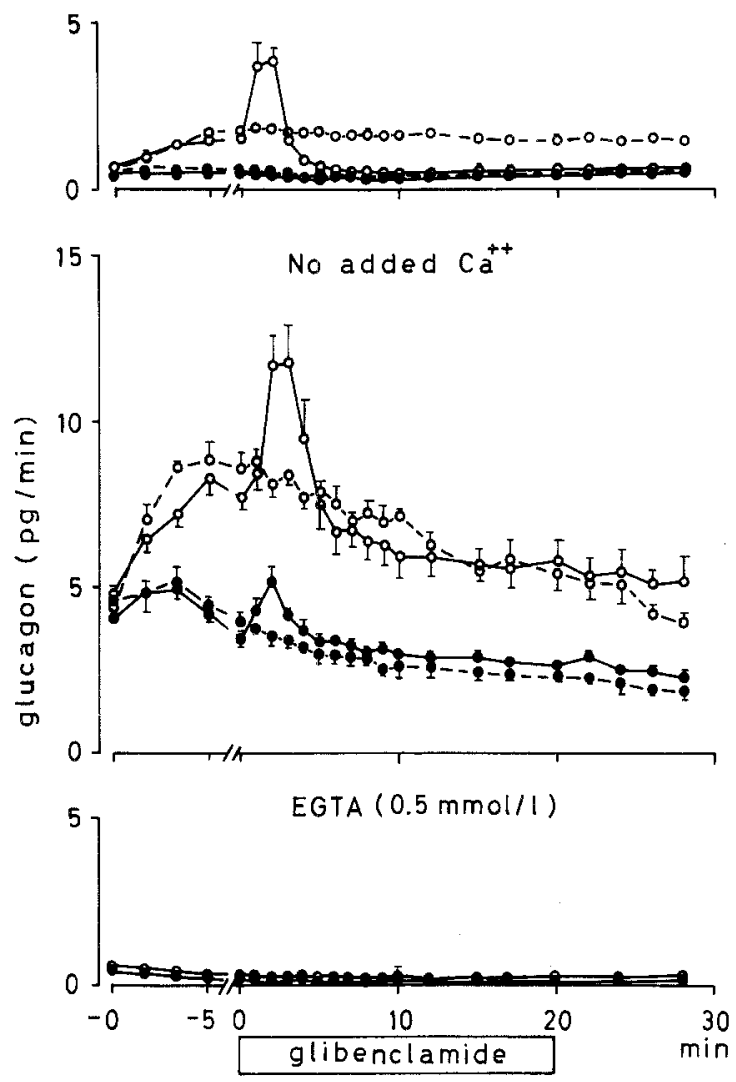

Fig. 3. Effect of variation of calcium concentrations on glibenclamide-induced glucagon secretion in the presence or absence of $3.3 \mathrm{mmol} / \mathrm{l}$ of glucose. Experimental conditions and symbols as in Fig. 1

mide-induced effects on secretion (Fig. 3, lower panel).

\section{Discussion}

Evidence accumulated in recent years emphazises the regulatory role of calcium ions in the release of hormones from the endocrine pancreas. Thus, under certain conditions this ion can per se induce insulin [11, 12], glucagon [7] or somatostatin [10] secretion in the absence of other stimulatory agents. Calcium also seems to be a prerequisite for the release of all pancreatic hormones in response to different secretagogues $[2,6,8]$. Current knowledge indicates that the uptake of calcium is essential for secretion, since insulin and glucagon secretion can be blocked by agents inhibiting calcium transport over the cell membrane $[19,20]$.

If the concentration of extracellular calcium is reduced solely by its absence in the medium, calcium is 
only provided from the tissues and albumin of the perfusate. Under these conditions, some release of insulin [21] and glucagon [13] may be evoked. Basal glucagon release has even been reported to be enhanced by a relative deficiency of extracellular calcium [13]. Little is known about the effect of low calcium on the secretion of the D cell.

Our findings show that the $\mathrm{A}$ and $\mathrm{B}$ cells respond to glibenclamide at a low calcium concentration $(0.25 \mathrm{mmol} / \mathrm{l})$. The findings that the insulin response to glibenclamide was preserved in the low calcium medium seem at first glance to diverge from previous observations using isolated islets where calcium removal markedly inhibited glibenclamide-induced insulin secretion [22, 23]. However, in the islet studies, provision of calcium to the incubation medium from albumin and tissue was probably less than in the present experiments since the albumin concentration was lower and since the exocrine pancreas was excluded. Thus, the results from the islet studies are likely to be in line with our findings with EGTA, showing that chelation of remaining calcium in calcium-deficient media leads to complete inhibition of insulin (and glucagon) release.

Stimulators other than sulphonylureas are less potent releasers at low than at normal calcium levels $[8,21]$, which we have confirmed with an identical experimental system (Efendić, Grill, Östensson, unpublished observations). The reason for these apparent differences in calcium dependency are not clear. It may indicate differences in stimulus-secretion coupling between sulphonylureas and other secretagogues. Alternatively it could be secondary to paracrine interactions between the islet cells.

A completely abolished D cell response to glibenclamide was observed after the omission of calcium in the medium. Thus, at low calcium concentration, the effects of glibenclamide differed between the responses of $\mathrm{B}$ and $\mathrm{A}$ cell and the D cell. These differences indicate that the role and handling of calcium is quantitatively different for glibenclamide-induced stimulation of the three cell types. Since the concentration of glibenclamide used in the present study exerts maximal or near-maximal effect both on insulin and somatostatin secretion (Efendić, Grill, Östensson, unpublished results), it seems unlikely that they solely reflect differences in the glibenclamide mediated dose-response curves for the respective hormones. The underlying mechanisms behind the divergent responsiveness of B and D cells remain to be clarified.

Our results imply a modulating effect of ambient calcium on the balanced secretion of pancreatic hormones under basal and stimulated conditions. In this context, it will be of interest (potentially also from a therapeutical point of view) to determine whether the relative effects of glibenclamide on insulin, glucagon and somatostatin secretion are altered by drugs that affect calcium transport.

Another possible implication concerns cell-to-cell interaction between $\mathrm{A}, \mathrm{B}$ and $\mathrm{D}$ cells in the pancreas. Paracrine effects of the secretory products of the different cell types have been proposed [24]. Experimental evidence supports the existence of intercellular communications between islet cells [25]. Paracrine interactions are difficult to test, one reason being that insulin and somatostatin are stimulated concomitantly in most experimental situations. A difference in the dependency on calcium for insulin and somatostatin secretion could be exploited as a tool for studies of whether the different hormone-producing cells interact locally in the pancreatic islet. In this context, the possibility should be considered that preservation of glibenclamide-induced insulin and glucagon secretion in a low compared with that in a normal calcium medium could be the result of the concomitant effect of calcium deficiency on somatostatin secretion, i.e. loss of D cell secretion. Glucose is known to modulate the pancreatic hormone response to other secretagogues. One of us (SE) recently studied the interaction of glucose and glibenclamide on the concomitant secretion of insulin, glucagon and somatostatin [5]. Differences were then noted between the response to glibenclamide in the absence of glucose compared with its presence in a moderately elevated concentration. Addition of glucose thus amplified the insulin but reduced the somatostatin response and abolished the bimodal (stimulation followed by inhibition) glucagon response to glibenclamide. In view of this profound influence of glucose on all aspects of glibenclamide-induced secretion, it seemed pertinent to study whether the calcium dependency of glibenclamideinduced secretion was, in fact, subject to alteration by glucose.

Our results indicate that the omission or addition of glucose did not affect our basic observation of the clear difference between the different islet cells types with regard to their dependency on calcium for secretion. Modulation by glucose was, however, evident. Thus, glibenclamide-induced insulin secretion was more augmented by glucose at low than at normal calcium concentration. The molecular basis for these observations is unclear. Since both glucose and sulphonylureas influence the uptake and efflux of ${ }^{45}$ calcium in islets [23, 26-28], it can probably be assumed that premises exist for such interactions on calcium fluxes that could affect the apparent calcium dependency of the insulin release process.

Acknowledgements. Excellent secretarial work was performed by Mrs. K. Breitholtz. This work was supported by the Swedish Medical Research Council (grant no 19X-00034-16B), the Nordic Insulin Foundation and the Swedish Diabetes Association. 


\section{References}

1. Unger RH, DobbsRE, OrciL (1978) Insulin, glucagon and somatostatin secretion in the regulation of metabolism. Ann Rev Physiol 40: 307-343

2. Hermansen K (1980) Secretion of somatostatin from the normal and diabetic pancreas. Diabetologia 19:492-504

3. Ipp E, DobbsRE, Arimura A, ValeW, Harris V, Unger RH (1977) Release of immunoreactive somatostatin from the pancreas in response to glucose, amino acids, pancreozymin-cholecystokinin, and tolbutamide. J Clin Invest 60:760-765

4. Samols E, Weir GC, Ramseur R, Day JA, Patel YC (1978) Modulation of pancreatic somatostatin by adrenergic and cholinergic agonism and by hyper- and hypoglycemic sulfonamides. Metabolism 27:2219-1221

5. EfendićS, Enzmann F, Nylén A, Uvnäs-Wallensten K, Luft R (1979) Effect of glucose/sulfonylurea interaction on release of insulin, glucagon, and somatostatin from isolated perfused rat pancreas. Proc Natl Acad Sci USA 76: 5901-5904

6. Iversen J, Hermansen K (1977) Calcium, glucose and glucagon release. Diabetologia 13: 297-303

7. Grodsky GM, Lundquist I, Fanska R, Pictet R (1977) Interrelationship of calcium and somatostatin in the secretion of insulin and glucagon. In: Foà PP, BajajJS, Foà NL (eds) Glucagon: Its role in physiology and clinical medicine. Springer, New York Heidelberg Berlin, pp 215-230

8. Grodsky GM, Bennett LL (1966) Cation requirements for insulin secretion in the isolated, perfused pancreas. Diabetes 15: 910 $\rightarrow 913$

9. Wollhein CB, Blondel B, Renold AE, Sharp GWG (1976) Calcium induced glucagon release in monolayer culture of the endocrine pancreas. Studies with ionophore A23187. Diabetologia 12: 287-294

10. Hermansen K, Christensen SE, ØrskovH (1979) Characterization of somatostatin release from the pancreas. The role of calcium and accetylcholine. Diabetologia 16:261-266

11. Devis G, Somers G, Malaisse WJ (1975) Stimulation of insulin release after raising intracellular calcium. Biochem Biophys Res Commun 67: 525-529

12. Hellman B (1976) Stimulation of insulin release after raising extracellular calcium. FEBS Lett 63:125-128

13. Leclercq-MeyerV, Marchand J, Malaisse WJ (1976) The role of calcium in glucagon release. Interactions between glucose and calcium. Diabetologia 12: 531-538

14. Loubatères AL, Mariani MM, Ribes G, de Malbose H, Chapal J (1969) Etude expérimentale d'un nouveau sulfamide hypoglycémiant particulièrement actif, le HB 419 ou glibenclamide. Diabetologia 5: 1-10

15. Umbreit WW, Burris RH, StaufferJF (1957) In: Manometric techniques. Burgess Publish Co, Minneapolis Minnesota, p149

16. Herbert V, Lau KS, GottliebCW, BleicherSJ (1965) Coated charcoal immunoassay of insulin. J Clin Endocrinol Metab 25: $1375-1384$
17. Faloona GR, Unger RH (1974) Glucagon. Radioimmunoassay technique. In: Jaffe BM, Behrman HR (eds) Methods of hormone radioimmunoassay. Academic Press, London New York pp 324-326

18. GrillV, Rundfeldt M, EfendićS (1981) Previous exposure to glucose enhances somatostatin secretion from the isolated perfused rat pancreas. Diabetologia 20: 495-500

19. Malaisse WJ, Herchuelz A, Devis G, Somers G, Boschero AC, Hutton JC, Kawazu S, Sener A, Atwater IJ, Duncan G, Ribalet B, Rojas E (1978) Regulation of calcium fluxes and their regulatory roles in pancreatic islets. Ann NY Acad Sci 307: 562-582

20. Leclercq-Meyer V, Marchand J, Malaisse WJ (1978) The role of calcium in glucagon release. Studies with Verapamil. Diabetes 27: $996-1004$

21. Lambert AE, Jeanrenaud B, Junod A, Renold AE (1969) Organ culture of fetal rat pancreas. II Insulin release induced by amino and organic acids, by hormonal peptides, by cationic alterations of the medium and by other agents. Biochim Biophys Acta 174: $540-553$

22. Grill V, Cerasi E (1978) Interacting effects of sulfonylureas and glucose on cyclic AMP metabolism and insulin release in pancreatic islets of the rat. J Clin Invest 61: 1346-1354

23. Henquin J-C (1980) Tolbutamide stimulation and inhibition of insulin release: studies of the underlying ionic mechanisms in isolated rat islets. Diabetologia 18: 151-160

24. Samols E, Marri G, Marks V (1965) Promotion of insulin secretion by glucagon. Lancet $2: 415-416$

25. Kohen E, Kohen C, Thorell B, Mintz D, Rabinovitch A (1979) Intercellular communication in pancreatic islet monolayer cultures: A microfluorometric study. Science 204: 862-865

26. Malaisse WJ, Mahy M, Brisson GR, Malaisse-Lagae F (1972) The stimulus-secretion coupling of glucose-induced insulin release. VIII Combined effects of glucose and sulfonylureas. Eur J Clin Invest 2: 85-90

27. Malaisse WJ, Pipeleers DG, MahyM (1973) The stimulus-secretion coupling of glucose-induced insulin release. XII Effects of diazoxide and gliclazide upon ${ }^{45}$ Calcium efflux from perifused islets. Diabetologia $9: 1-5$

28. Hellman B (1981) Tolbutamide stimulation of ${ }^{45} \mathrm{Ca}$ fluxes in microdissected pancreatic islets rich in $\beta$-cells. Mol Pharmacol 20: $83-88$

Received: 20July 1981

and in revised form: 20 January 1982

Dr. S. Efendić

Department of Endocrinology

Karolinska Hospital

S-104 01 Stockholm, Sweden 